УДК 140.8

DOI 10.18413/2712-746X-2020-45-4-667-674

\title{
Пандемия коронавируса как следствие западных мировоззренческих установок
}

\author{
Манохин Д.К., Стручаев М.В. \\ Белгородский национальный исследовательский университет \\ 308015, Белгород, ул. Победы 85, Россия \\ E-mail: struchaev@bsu.edu.ru
}

\begin{abstract}
Аннотация. Пандемия не первый раз происходит в истории человечества. Каждый раз она сопровождается переоценкой смыслов бытия и способов решения различных проблем. Работ, осмысливающих мировоззренческие истоки пандемии коронавируса немного, поскольку сам COVID-19 появился сравнительно недавно, в конце 2019 года. В связи с этим авторы рассматривают появление пандемии коронавируса как результат развития мирового сообщества по западному пути. Основными мировоззренческими установками жизни и деятельности здесь становятся принципы индивидуализма, гедонизма и преобразования мира. При этом авторы сравнивают западный подход и традиционный восточный подход, используя при рассмотрении обозначенных выше идей философию даосизма. Даосская философия хорошо объясняет причины, которые привели к пандемии, выдвигает противоположные установки в качестве способа жизни и деятельности. Авторы приходят к выводу, что появление новых вирусов - естественный ответ природы на определенное антропогенное воздействие и человеку придется к ним адаптироваться, выработать различные системы защиты, как внешние, так и внутренние. Для этого необходимо пересмотреть характер своего взаимодействия с окружающим миром. Это в итоге приведет человечество к новой, более высокой ступени своего развития.
\end{abstract}

Ключевые слова: коронавирус, эпидемия, мировоззрение, индивидуализм, преобразование мира, гедонизм, даосизм.

Для цитирования: Манохин Д.К., Стручаев М.В., 2020. Пандемия коронавируса как следствие западных мировоззренческих установок. NOMOTHETIKA: Философия. Социология. Право, 45 (4): 667-674. DOI 10.18413/2712-746X-2020-45-4-667-674

\section{The coronavirus pandemic as a consequence of western worldviews}

\author{
Manokhin D.K., Struchaev M.V. \\ Belgorod National Research University, \\ 85 Pobedy St, Belgorod, 308015, Russia \\ struchaev@bsu.edu.ru
}

\begin{abstract}
This is not the first time a pandemic has occurred in the history of mankind. Each time it's accompanied by a revaluation of the life's meaning and the ways to solve various problems. There are few works that comprehend the philosophical origins of the coronavirus pandemic, since COVID-19 itself appeared relatively recently, at the end of 2019. The authors attempt to consider the occurrence of the coronavirus pandemic as a result of the world community development along the Western path. The principles of individualism, hedonism and the world transformation become the main philosophical attitudes of life and activity. At the same time, the authors compare the Western approach and the traditional Eastern one, using Taoism philosophy when considering the listed ideas. Taoist philosophy explains well the reasons that led to the pandemic, puts forward opposite attitudes as a way of life and
\end{abstract}


activity. The authors also conclude that the appearance of new viruses is a nature's expected response to a certain anthropogenic impact. And a human will have to adapt to them, develop various protection systems, both external and internal. To do this, we need to reconsider the nature of your interaction with outer world. This will eventually lead humanity to a new, higher stage of its development.

Key words: coronavirus, epidemy, worldview, individualism, world transforming, hedonism, Taoism.

For citation: Manokhin D.K., Struchaev M.V. 2020. The coronavirus pandemic as a consequence of western worldviews. NOMOTHETIKA: Philosophy. Sociology. Law series. 45 (4): 667-674 (in Russian). DOI 10.18413/2712-746X-2020-45-4-667-674

\section{Введение}

Пандемия не первый раз происходит в истории человечества. Каждый раз она сопровождается переоценкой смыслов бытия и способов решения различных проблем. Происходящее в настоящее время ставит под сомнение многие принципы западной культуры и философии с их индивидуализмом, прагматизмом, ориентацией на сегодняшний день, на моментальные выгоды, на получение сиюминутных удовольствий и многое другие. И если посмотреть на сложившую ситуацию с приходом пандемии COVID19, то мы увидим, что западный подход уже не работает. «Осмысление подобной ситуации предполагает новую оценку развития европейской цивилизации, ценности которой в отношении к человеку, природе, познавательному процессу и т.д., казавшиеся неизменным условием прогресса общества и улучшения жизни и не менявшиеся в течение многих веков, ставятся под сомнение...» [Стручаев, 2018, с. 188].

С другой стороны, существуют восточная философия и восточные философские и культурные традиции, которые по-другому рассматривают мир и человека и дают ответы на многие актуальные вопросы сегодняшней действительности. Что является самым важным для человека? Что более ценно - жизнь одного человека или другого, интересы отдельной личности или государства в целом? Что делать человеку перед лицом надвигающейся смертельной угрозы? Что на самом деле нужно человеку, а без чего он может обойтись? В чем смысл нашей жизни? Эти вопросы затрагивают все сферы жизни человека и общества и являются мировоззренческими. Они требуют осмысления и быстрых, не всегда популярных решений. На многие из этих вопросов философы уже дали различные ответы, на некоторые предстоит найти ответ обществу в целом.

Цель данной работы авторы видят в том, чтобы показать, что пандемия коронавируса является следствием западного подхода к жизни и деятельности человека, а также попытаться обозначить векторы выхода из сложившейся ситуации.

Постановка данной цели определила структуру и задачи работы, а именно: описать понятие «мировоззрение», обозначив его основные характеристики; далее рассмотреть имеющиеся установки жизни и деятельности в рамках обозначенных характеристик, параллельно соотнося эти установки с наличной ситуацией в мире, которая приводит к вспышке пандемии. Для того, чтобы сравнить западные мировоззренческие установки и традиционные восточные, используются идеи философии даосизма. Также даосская философия задействуется в осмысления текущей ситуации с появлением и распространением коронавируса. По мнению авторов, даосизм хорошо объясняет причины, которые привели к пандемии, выдвигает противоположные установки в качестве способа жизни и деятельности. Авторы считают, что такие мировоззренческие установки, будут способствовать минимизации рисков повторения пандемии в будущем.

Поставленные цели и задачи определили и используемые в работе материалы. Для пояснения термина мировоззрения и рассматриваемых в нем характеристик используются различные философские словари. В качестве основных материалов используется традици- 
онная литература по даосизму (собрание текстов по древнекитайской философии и другие источники), статьи и книги по мировоззренческим установкам западной и восточной культуры (работы таких авторов, как Г. Гессе, Дж. Нидам, Л. Уайт, С.Г. Кара-Мурза), а также статьи в журналах, исследования и книги по пандемиям (посмотреть по-другому на многие проблемы, а также впоследствии соотнести их с идеями даосизма помогла книга Сони Шах «Пандемия»). Авторы используют различные материалы из сети интернет, интервью и блоги отечественных и иностранных философов, электронные издания, а также некоторые другие онлайн источники, без которых рассмотрение ситуации с появлением и распространением COVID19 можно считать неполным.

\section{Преобразование мира}

В названии статьи фигурирует термин «мировоззрение», и следует сначала пояснить, о чем идет речь. Говоря о мировоззрении, мы понимаем, что это - система взглядов на мир и место человека, общества и человечества в нем, на отношение человека к миру и самому себе ${ }^{1}$.

Этим взглядам и отношению соответствуют принципы человеческой деятельности (куда можно отнести, например, западную установку на преобразование мира); основные жизненные позиции и идеалы человека (здесь мы рассматриваем принцип индивидуализма); ценностные ориентации человека (здесь, несомненно, будет присутствовать западный гедонизм как один из главных смыслов жизни). Попробуем рассмотреть каждый из этих срезов.

Установка на преобразование мира является одним из основных компонентов западной философской и культурной традиции. С эпохи Нового времени на Западе доминировала парадигма, основной идеей которой было активное преобразование человеком окружающего мира [Уайт, 1990]. При этом природа всегда понималась как противостоящая человеку. Постепенно данная идея трансформировалась в мировоззренческую установку западной (техногенной) культуры. В рамках такой научной парадигмы человеку следовало подчинить природу и использовать ее для удовлетворения собственных потребностей [Кара-Мурза, 1990]. Не стоит забывать, что западная культура в целом базируется на антропоцентризме - мировоззренческой установке, согласно которой человек является центром и высшей целью мироздания, поэтому он самостоятелен и свободен в своих поступках и действиях ${ }^{2}$.

Несомненно, такой принцип деятельности имел свои плюсы и способствовал общественному прогрессу, обоснованию идей свободы и личной инициативы, а в перспективе обеспечивал постоянное улучшение жизни людей. Но такой подход может работать до определенного момента: природные ресурсы и возможности окружающей среды ограниченны, а человеческие запросы - нет. Постоянный рост потребностей, расширение производства, поиски оптимальных с точки зрения финансовых вложений принципов деятельности в итоге приводят к различным глобальным проблемам.

Сегодня очевидно то, что и коронавирус уже стал одной из основных глобальных проблем и влияет на большинство сфер общественной жизни и почти все страны мира. Отчасти это результат развития мирового сообщества по западному пути, и «именно получение различных благ от покоренного нами мира, приводит его на путь саморазрушения» [Nancy J.-L. Mal and power. - перевод авт.]. Здесь мы имеем в виду активное вмешательство в природные процессы, зачастую бесконтрольное изменение живых организмов (геном), огромное негативное антропогенное и техногенное воздействие на различные

${ }^{1}$ Словари. Философская энциклопедия. URL: https://rus-philosophical-enc.slovaronline.com 
биологические сообщества и биосферу в целом: вырубка лесов, расширение возделываемых земель, появление животноводческих хозяйств в местах, где их никогда не было, расширение территорий городов, отсутствие единого экологического подхода и координации в системе охране природы. Это в свою очередь приводит к различным негативным последствиям уже для самого человека: во-первых, к ухудшению экологической обстановки и сокращению видового разнообразия (как известно, некоторые виды являются своего рода буфером между человеком и различными микроорганизмами, бактериями и вирусами); во-вторых, к взаимодействию видов, ранее не контактировавших между собой (при этом взаимодействуют и различные микроорганизмы, бактерии, вирусы, характерные для этих видов). В результате появляются новые микроорганизмы и вирусы, в частности, новый коронавирус.

На Востоке развивались иные представления о мире, человеке, их взаимосвязи, которые приводят и к другим установкам человеческой деятельности. Для восточной культуры (здесь мы уже, к сожалению, не имеем в виду Китай и другие восточные страны в традиционном понимании, так как уже несколько десятилетий они развиваются по западному пути) совсем не был характерен принцип силового воздействия на природу, равно как и идея ее подчинения. На Востоке люди «...не отделяли себя от природы и не пытались насильственно вторгаться в ее тайны, они никогда не противопоставляли себя природе и не были враждебны ей, а всегда оставались частью ее...» (Г. Гессе. Игра в бисер). А силовые воздействия на природу, характерные для западной научной рациональности, на востоке рассматривались как малоперспективные [Нидам, 1966]. С позиции того же даосизма, основная цель человека - не преобразование природы, а глубинное понимание смысла и пути развития природы, мира и самого себя. Эта установка выразилась в появлении в даосизме концепции недеяния или «у-вэй». Но это отнюдь не отсутствие действия, как такового, а, наоборот, естественное действие, совершаемое в рамках основного закона природы Дао, в русле которого и развивается мир. «Совершенно мудрый, совершая дела, предпочитает недеяние. Осуществление недеяния всегда приносит спокойствие» [Древнекитайская философия, 1972, с. 115-116].

Если мы попробуем соотнести эту идею с текущей ситуацией с пандемией коронавируса, то с очевидностью признаем, что человечеству следует более внимательно и аккуратно относиться к своей деятельности во многих сферах [Beilin et al., 2018], которая зачастую может приводить к различным глобальным изменениям. Речь здесь идет и о генетических исследованиях с непредсказуемыми последствиями (одна из версий того, как появился коронавирус, пусть отчасти и фантастическая, - эксперименты с генетическим материалом), и о негативном влиянии на различного рода экосистемы, что приводит к их сокращению или сосуществованию таких видов, которые в дикой природе никак не взаимодействуют (еще одна версия появления COVID19 - взаимодействие ранее не соприкасавшихся друг с другом видом животных и поражающих их микробов), и о некоторых других факторах. И в данной ситуации человеку следует предпринять меры по защите природы, разработать «Новый зеленый курс в масштабах планеты» [Браттон, 2020], поскольку от этого зависит состояние не только самого человека, но и состояние различных видов животных и растений, которые человек употребляет в пищу (очевидно, что поражение, например, флоры будет, возможно, еще более трагично, чем сама пандемия).

\section{Индивидуализм}

Еще одной важной характеристикой западной культуры является индивидуализм, когда интересы отдельного человека, отдельной личности ставятся выше интересов раз- 
личных социальных групп и общностей ${ }^{1}$. Рассматривая идею индивидуализма, следует обозначить два момента.

Во-первых - это индивидуализм отдельной личности по отношению к другим индивидам. В ситуации с пандемией COVID-19 такой подход становится очень опасным, поскольку индивид порой даже не задумывается о последствиях своего поведения, о его влиянии на жизнь других людей (взять хотя бы правило самоизоляции, если была вероятность контакта с уже заболевшим, но некоторые это правило просто игнорировали). Все мы живем в социуме, и здесь прослеживается прямая зависимость благополучия социума от действий отдельных индивидов. Статистические модели распространения коронавируса показывают, что «в случае с COVID-19 опасностью является заражение, а его риск не только и не столько индивидуальный, сколько коллективный [Браттон, 2020].

Индивидуализм не работает в случае эпидемии, потому что, ставя свои интересы на первый план, человек подвергает риску жизни других людей. Очевидно, что мы все постоянно находимся в контакте друг с другом и обмениваемся различными биологическими субстанциями (выдыхаемый воздух, волосы, клетки эпителия, слюна и т.д.), в том числе вирусами, представляющими опасность для жизни. Эпидемия приводит к пониманию того, какая тесная связь существует между людьми в социуме, и неверные шаги отдельного индивидуума могут пагубно отразиться на состоянии общества в целом.

Во-вторых - это так называемый индивидуализм отдельных социальных групп по отношению к другим социальным группам. Это применимо и в ситуации с международными отношениями в период пандемии. В качестве иллюстрации можно взять пример США с такой системой здравоохранения, «где существует в основном частная медицина и потому невозможны централизованные решения» и где «произошел полный провал с коронавирусом» [Щипков, 2020, с. 15], поскольку в борьбе с эпидемией на первый план выходят согласованность действий, контролируемое соблюдение карантинных мер. Еще одним примером индивидуализма в пределах какого-либо сообщества в ситуации с пандемией коронавируса можно назвать «попытку приобретения Трампом исключительного права для США на использование вакцины компании CureVac» [Butler J. Capitalism has its limits. - перевод aвm.]. Подобный западный подход в современных реалиях неприемлем, не говоря уже об этической стороне этого вопроса. К тому же широкое и интенсивное распространение вируса как раз явилось следствием идей индивидуализма, поскольку не срабатывают имеющиеся у человечества способности к сотрудничеству.

Это хорошо перекликается с идеями даосизма. Согласно ему, весь мир - это единый целостный организм, все части которого взаимодействуют друг с другом. «Все пронизывает единый путь - Дао, все связано между собой. Жизнь едина, и стремление каждой ее части должно совпадать со стремлением целого» [Древнекитайская философия, 1972, с. 26]. Недуг отдельного человека или отдельного государства может привести к болезни всех других людей, всех других государств. «Одним из изменений, которые нас ждут, станет эпидемиологический взгляд на общество, который в меньшей степени сосредоточен на паре "индивид - общество" и рассматривает общество как совокупное целое... Статистические модели и интерфейсы, показывающие пути распространения заражения, рисуют чёткий портрет событий. Благодаря этой статистике становится очевидно, что все мы - единое и очень глубоко связанное целое» [Браттон, 2020].

\section{Гедонизм}

Еще одна установка западной культуры - это гедонизм, когда наслаждение считается высшим благом ${ }^{2}$, а один из основных смыслов существования - получение чувствен-

\footnotetext{
${ }^{1}$ https://rus-philosophical-enc.slovaronline.com/3977

${ }^{2}$ https://rus-philosophical-enc.slovaronline.com/2777
} 
ных удовольствий. Но реальность ворвалась в жизнь человека и рукой коронавируса вынула его из привычного аквариума [Мамардашвили, 1995, с. 13], аквариума удовольствий и наслаждений. Он не может пойти или поехать, как обычно, в ресторан, кинотеатр, к друзьям, в библиотеку, баню, на курорт, салон массажа, да просто в тот же магазин: что-то не работает, граница на замке, фильмы не выпускают, да и в магазине есть риск заразиться тем, с чем многие не смогли справиться.

Человек оказывается перед лицом смерти, и это не какая-то далекая перспектива или нечто, касающееся кого-то другого, а самая настоящая реальность. В такие экзистенциальные моменты волей-неволей начинаешь задумываться о самой жизни, о ее смысле. Смерть знакомых людей, близких, даже их возможная смерть, открывает глаза людям, заставляет «осознать себя существами содержательно, абсолютно, безмерно и единственно конечными, а не бесконечно всемогущими - это один из уникальных способов придания смысла нашему существованию» (Nancy J.-L. Mal and power. - nеревод aвm.). Параллельно отсеивается все лишнее, напускное, не имеющее значения в данной ситуации выбора между жизнью и смертью. В таких ситуациях человек по-новому способен посмотреть на свою жизнь, на себя, на имеющиеся у него ценностные установки, идеалы, на свои поступки и на жизнь в целом. И задуматься над теми проблемами, которые раньше были бесконечно далекими: о своем поведении в период эпидемии, о смысле жизни, о добре, зле и многих других вопросах, которые откладывались в долгий ящик как неактуальные на данный конкретный момент, выходя при этом на уровень этического сознания. Ответы на эти вопросы нужны для того, чтобы решить для самого себя, как действовать дальше и что обо всем этом думать. В таком ракурсе рассмотрения, «пандемия - явление прежде всего философское. Высшей целью в ней является не выживание, а понимание и изменение, смена глубинной метафизической ориентации. Смена философского и экзистенциального режима. Это философский дар чумы» [Дугин, 2020].

Данное состояние человека и подобные вопросы по сути вплотную подводят нас к идее даосской философии о том, что человек, в первую очередь познающий человек, - это нравственное существо. И необходимым условием познания, условием возможности воздействия на те или иные процессы природы, является этика, этическое сознание. А основной закон Дао при этом выступает основным этическим принципом.

Вопрос о взаимосвязи нравственности и поиска истины постоянно обсуждался и в западной философской мысли, но при этом само постижение истины там уже считалось нравственным. А европейская научная революция впоследствии разделила этику и науку и привела к тому, что «мир стал более опасным» [Нидам, 1966, с. 155]. На Востоке же только наличие высокого уровня нравственности являлось необходимым условием и отправной точкой познания мира. При этом здесь не было противопоставления субъекта и объекта познания. Человек не был внеположным миру, он всегда являлся органичной его частью. А в зависимости от тех или иных действий человека, природа, следуя закону Дао, «может и повернуться лицом к человеку, и отвернуться от него», поскольку «небо действует в зависимости от поступков людей» [Го Юй, 1987, с. 298]. Это своеобразный ответ, «когда природа атакует нас вирусами, она в каком-то смысле делает с нами то, что мы сделали с ней» [Žižek S. Monitor and punish? Yes, please! - перевод авт.].

\section{Заключение}

Как же действовать человечеству в уже случившейся реальности? «Как от проказницы Зимы, // Запремся также от Чумы!» (Пушкин А.С., Пир во время чумы). Это действенный вариант в ближайшей перспективе, на период карантина, для минимизации распространения инфекции, для того, чтобы система здравоохранения могла справиться со всеми нуждающимися в помощи. Но в дальней перспективе такой подход скорее всего не сработает! COVID-19 - это случившаяся реальность, как сейчас грипп, например, или как когда-то чума, и каждому придется с ним столкнуться. «А что такое, в сущности, чума? 
Тоже жизнь...» (Камю А. Чума). Здесь мы имеем в виду то, что различные патогены и вирусы - это тоже формы жизни, которые наряду с природными явлениями могут воздействовать на те или иные процессы в мире. По сути, вспышка коронавируса - это вполне естественный (с биологической точки зрения) природный процесс, к которому привели определенные условия. А появление Ковид19 иллюстрирует даосскую идею о наличии изначальных взаимодействующих друг с другом полярных сил природы Инь и Ян, которые в свою очередь приводят к появлению всего живого. Очень хотелось бы думать, что вирусы, в частности COVID-19, это Инь. Почему? Тогда сам человек будет уже выступать элементом Ян. При этом все живые виды находятся в постоянном развитии, противоборстве друг с другом, адаптируются к изменяющимся условиям среды (например, к изменению температуры, изменению химического состава среды). У микроорганизмов происходит выработка устойчивости к медицинским препаратам, вирусы мутируют в процессе их циркуляции в природе и социуме и т.д., и т.п. То же самое и с человеком: человек - это тоже живой вид, он подчиняется тем же законам и так же адаптируется к меняющимся условиям среды. Такое взаимодействие и противоборство микроорганизмов и человека было на всем протяжении человеческой истории, иллюстрируя взаимодействие элементов «Инь - Ян». И несмотря на то, что человечество чаще всего было не готово к такому вызову, оно, так или иначе, справлялось с пандемией (не смотря на большое количество умерших в такие периоды). С точки зрения даосизма - это тоже естественный ход событий, постоянное взаимодействие и противоборство изначальных, полярных сил природы. Важный момент: элемент Ян всегда в себе содержит зачаток элемента Инь, и наоборот. Другими словами, победить вирус нельзя, к нему можно адаптироваться, выработать различные системы защиты, как внешние, так и внутренние. Подобное взаимодействие человека и различных микроорганизмов и вирусов было и будет всегда. Эти единство и борьба приводят к изменению как отдельного человека, так и человечества в целом, выработке коллективного иммунитета и переходу на новую, более высокую ступень своего развития, преодолевая подобные вызовы, различные болезни и самих себя.

\section{Список источников}

1. Браттон Б. 2020. Восемнадцать уроков карантинного урбанизма. URL: https://strelkamag.com/ru/article/18-urokov-karantinnogo-urbanizma (дата обращения: 26.10.2020).

2. Го Юй. 1987. Речи царств. М., Наука, 472 с.

3. Древнекитайская философия. Собрание текстов. Т. 1. 1972. М., Мысль, 363 с.

4. Дугин А.Г. 2020. Дар чумы (пандемия и экзистенциальная философия). Электронная статья. URL: https://www.geopolitica.ru/article/dar-chumy-pandemiya-i-ekzistencialnaya-filosofiya (дата обращения: 26.10.2020).

5. Butler J. 2020 Capitalism has its limits. URL: https://www.versobooks.com/blogs/4603capitalism-has-its-limits (дата обращения: 26.10.2020)

6. Nancy J.-L. 2020. Mal and power. URL: https://thephilosophicalsalon.com/mal-and-power (дата обращения: 26.10.2020)

7. Žižek S. 2020. Monitor and punish? Yes, please! URL: https://thephilosophicalsalon.com /monitor-and-punish-yes-please (дата обращения: 26.10.2020)

\section{Список литературы}

1. Кара-Мурза С.Г. 1990. Наука и кризис цивилизации. Вопросы философии, 9: 3-15.

2. Мамардашвили М.К. 1995. Лекции о Прусте (психологическая топология пути). M., Ad Marginem, $548 \mathrm{c}$.

3. Нидам Дж. 1966. Общество и наука на Востоке и на Западе. В кн.: Наука о науке: сборник статей. Под ред. В. Н. Столетова. М., Прогресс: 155-160. 
4. Стручаев М.В. 2018. Новые стратегии человеческой деятельности: даосская философская традиция и современная научная парадигма. Научные ведомости БелГУ: Философия. Социология. Право, 43 (1): 188-193. DOI: 10.18413/2075-4566-2018-43-1-188-193

5. Уайт Л. 1990. Исторические корни нашего экологического кризиса. В кн.: Глобальные проблемы и общечеловеческие ценности. М., Прогресс: 188-202.

6. Щипков А.В. 2020. Политическая философия коронавируса. Международная жизнь, 5: $12-19$.

7. Beilin M.V., Chistyakova E.Y., Gazniuk L.M., Kuznetsov A.V., Manohin D.K., Struchaev M.V. 2018. Anthropogenic activity: risks and protection safety of human life. Revista Publicando, 5No 16(1): 598-605.

\section{References}

1. Kara-Murza S.G. 1990. Nauka i krizis civilizacii [Science and the civilization crises]. Voprosy filosofii, 9: 3-15.

2. Mamardashvili M.K. 1995. Lekcii o Pruste (psihologicheskaya topologiya puti) [Lections about Proust (psychological topology of the path)]. M., Publ. Ad Marginem, 548 p.

3. Nidam Dzh. 1966. Obshchestvo i nauka na Vostoke i na Zapade [Society and science in the East and West]. In: Nauka o nauke. Ed. V.N. Stoletova. M., Publ. Progress: 155-160.

4. Struchaev M.V. 2018. New strategies of human activity: philosophical tradition of Taoism and contemporary scientific paradigm. Nauchnye vedomosti BelGU: Filosofiya. Sociologiya. Pravo, 43 (1): 188-193 (in Russian) DOI: 10.18413/2075-4566-2018-43-1-188-193

5. Uajt L. 1990. Istoricheskie korni nashego ekologicheskogo krizisa [Historical origins of our ecological crises]. In: Global'nye problemy i obshchechelovecheskie cennosti [Global problems and universal values]. M., Publ. Progress: 188-202.

6. SHCHipkov A.V. 2020. Politicheskaya filosofiya koronavirusa [Political philosophy of coronavirus]. International affairs, 5: 12-19.

7. Beilin M.V., Chistyakova E.Y., Gazniuk L.M., Kuznetsov A.V., Manohin D.K., Struchaev M.V. 2018. Anthropogenic activity: risks and protection safety of human life. Revista Publicando, 5No 16(1): 598-605.

\section{ИНФОРМАЦИЯ ОБ АВТОРАХ}

Манохин Дмитрий Константинович, кандидат философских наук, доцент кафедры философии и теологии НИУ «БелГУ», Белгород, Россия

Стручаев Михаил Васильевич, кандидат философских наук, доцент кафедры философии и теологии НИУ «БелГУ», Белгород, Россия

\section{INFORMATION ABOUT THE AUTHORS}

Dmitry K. Manokhin, candidate of philosophy, associate professor of Belgorod State National Research University, Belgorod, Russia

Mikhail V. Struchaev, candidate of philosophy, associate professor of Belgorod State National Research University, Belgorod, Russia 